Pesq. Vet. Bras. 29(3):241-245, março 2009

\title{
Plasma rico em plaquetas no tratamento de tendinite induzida em eqüinos: avaliação ultra-sonográfica ${ }^{1}$
}

\author{
Leandro Maia ${ }^{2}$, Maria V. de Souza ${ }^{2 *}$,Geraldo E.S. Alves ${ }^{3}$, José I.R. Júnior ${ }^{4}$, \\ Aécio C. de Oliveira ${ }^{2}$ Bruna M. Zandim² e Yamê F.R.S. da Silva²
}

\begin{abstract}
Maia L., Souza M.V., Alves G.E.S., Júnior J.I.R., Oliveira A.C., Silva Y.F.R.S. \& Zandim B.M. 2009. [Platelet-rich plasma in the treatment of induced tendinitis in equines: Ultrasonographic evaluation.] Plasma rico em plaquetas no tratamento de tendinite induzida em eqüinos: avaliação ultra-sonográfica. Pesquisa Veterinária Brasileira 29(3):241-245. Setor de Clínica e Cirurgia de Grandes Animais, Departamento de Veterinária, Universidade Federal de Viçosa, 36570-000 Viçosa, MG, Brazil. E-mail: msouza@ufv.br

The objective of the study was to evaluate the effect of platelet-rich plasma (PRP) in the treatment of induced tendinitis in the superficial digital flexor tendon (SDFT) of horses through ultrasonographic evaluation. Thus, six 8 to15-year-old healthy gelding horses $(\bar{x}=12$ years) were used. Tendinitis of the SDFT was provoked in both forelimbs via intratendineous administration of $2.5 \mathrm{mg}$ of collagenase $\left(2.5 \mathrm{mg} \mathrm{mL}^{-1}\right)$, what was considered as beginning of the experimental phase. Twelve days after induced tendinitis, the horses were submitted to two treatments: (1) in the lesion caused in the right SDFT (treated group, TG), $2.5 \mathrm{~mL}$ of

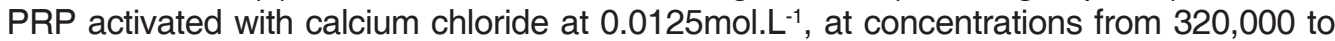
500,000 platelets. $\mu \mathrm{L}^{-1}$, were administered; (2) in the tendinitis of the left SDFT (control group, CG), $2.5 \mathrm{~mL}$ of $0.9 \%$ saline solution was administered. After 5 days, the animals were submitted to controlled and progressive physical activity during 30 days. Ultrasonographic examinations were carried out before and after tendinitis induction (48 hours after and on experimental days 7, 12, 14, 21 28, 35 and 42), with tendon crosssectional area (CSA), lesion cross-sectional area (L-CSA), L-CSA percentage, severity and echogenicity of the lesion, as well as collagen fiber alignment being evaluated. The result revealed reduction $(P<0.05)$ in the L-CSA and in the degree of lesion echogenicity in function of time, but with difference $(P<0.05)$ between groups only for L-CSA, with smaller values in TG. The treatment with PRP promotes greater reduction in the area of the lesion measured by ultrasound.
\end{abstract}

INDEX TERMS: Horses, tendon, ultrasound, growth factors, healing.

RESUMO.- O objetivo deste trabalho foi estudar o efeito do plasma rico em plaquetas (PRP) no tratamento da tendinite induzida no tendão do músculo flexor digital superficial (TFDS) de eqüinos mediante avaliação ultrasonográfica. Para isso foram utilizados seis eqüinos

\footnotetext{
${ }^{1}$ Recebido em 29 de setembro de 2008.

Aceito para publicação em 9 de outubro de 2008.

2 Setor de Clínica e Cirurgia de Grandes Animais, Departamento de Veterinária, Universidade Federal de Viçosa (UFV), Viçosa, MG 36570000, Brasil. *Author for correspondence: msouza@ufv.br

${ }^{3}$ Departamento de Clínica e Cirurgia Veterinária, Universidade Federal de Minas Gerais (UFMG), Belo Horizonte, MG 31270-901, Brasil.

${ }^{4}$ Departamento de Informática, UFV, Viçosa, MG.
}

hígidos machos castrados, com idade de 8-15 anos ( $\mathrm{x}=12$ anos). A tendinite do TFDS foi provocada em ambos os membros torácicos, mediante a administração intratendínea de $2,5 \mathrm{mg}$ de colagenase $\left(2,5 \mathrm{mg} \cdot \mu \mathrm{L}^{-1}\right)$, sendo esse procedimento considerado o início da fase experimental. Doze dias após a indução da tendinite, os animais foram submetidos a dois tratamentos: sendo que na lesão efetuada no TFDS direito (grupo tratado, GT), foram administrados $2,5 \mathrm{~mL}$ de PRP ativado com cloreto de cálcio a $0,0125 \mathrm{~mol} . \mathrm{L}^{-1}$, contendo concentrações variando de 320.000 a 500.000 plaquetas. $\mu \mathrm{L}^{-1}$; na tendinite do TFDS esquerdo (grupo controle, GC), foram injetados $2,5 \mathrm{~mL}$ de solução salina a $0,9 \%$. Após cinco dias, os 
animais foram submetidos à atividade física controlada e progressiva durante 30 dias. Os exames ultrasonográficos foram realizados antes e após indução da tendinite (48 horas após e no $7^{\circ}, 12^{\circ}, 14^{\circ}, 21^{\circ}, 28^{\circ}, 35^{\circ}$, $42^{\circ}$ dias do experimento), sendo avaliado a área transversal do tendão (ATT), área transversal da lesão (ATL), o percentual da ATL, a intensidade e ecogenicidade da lesão, assim como o paralelismo das fibras colágenas. Os resultados revelaram redução $(P<0,05)$ da ATL e do grau de ecogenicidade da lesão em função do tempo, mas com diferença $(P<0,05)$ entre grupos apenas para ATL, com valores menores no GT. O tratamento com PRP proporciona maior redução da área da lesão, mensurada por ultra-sonografia.

TERMOS DE INDEXAÇÃO: Cavalos, tendão, ultra-sonografia, fatores de crescimento, cicatrização.

\section{INTRODUÇÃO}

O plasma rico em plaquetas (PRP) e o concentrado de plaquetas (CP) é uma fonte de fácil aquisição e baixo custo de diversos fatores de crescimento, importantes na reparação tecidual, devido à ação mitogênica, quimiotáxica e neovascular.

O PRP é derivado do sangue total, podendo conter entre três a cinco vezes mais plaquetas que os níveis fisiológicos (Marx et al. 1998, Gonshor 2002, Kevy \& Jacobson 2004) que, nos eqüinos, podem variar entre 100.000 e 350.000 plaquetas. $\mu L^{-1}$ (Feldman et al. 2000). Esse componente pode ser obtido mediante uma (Camargo et al. 2002, Pagliosa \& Alves 2007) ou duas centrifugações (Nunes Filho et al. 2007, Pagliosa \& Alves 2007, Barbosa et al. 2008, Maia 2008) de 200-2000g, durante 3-5 minutos. Na opinião de Anitua et al. (2004) concentrações superiores a 300.000 plaquetas. $\mu \mathrm{L}^{-1}$ são suficientes para o preparo do PRP.

A ultra-sonografia é uma técnica de diagnóstico por imagem de auxilio na detecção e no acompanhamento de lesões que afetam o aparelho locomotor de eqüinos. Esta técnica permite determinar o local exato da lesão, e quantificar a extensão e a intensidade da mesma, além de possibilitar o monitoramento do processo de reparação tecidual durante o período de tratamento (Marr et al. 1993). Segundo Wrigley (2006) são necessárias imagens de alta resolução, particularmente para a identificação de lesões discretas, visto que tendões e ligamentos são estruturas relativamente pequenas. Os transdutores com freqüência de $7,5 \mathrm{MHz}$ são adequados para avaliação de tendões e ligamentos, por proporcionarem a obtenção de uma imagem com boa resolução. Na opinião de Genovese \& Rantanen (1998), a utilização do standoff pad (distanciador) é essencial quando se deseja estudar a superfície do tendão do músculo flexor digital superficial (TFDS).

O objetivo deste trabalho foi determinar, mediante avaliação ultra-sonográfica, o efeito do PRP no tratamento da tendinite induzida no TFDS de eqüinos.

\section{MATERIAL E MÉTODOS}

Foram utilizados seis eqüinos mestiços hígidos machos, castrados e com idade entre oito e 15 anos $(12 \pm 2,28)$, selecionados mediante avaliação de variáveis clínicas e exame específico do aparelho locomotor, bem como estudo ultra-sonográfico da região metacárpica palmar dos membros torácicos.

A tendinite do TFDS foi induzida nos membros torácicos direito (MTD) e esquerdo (MTE) de todos os animais, mediante a administração de 2,5mg de colagenase (Colagenase tipo 1: C$0130^{\circledR}$, Sigma Pharmaceutical) diluída em $1 \mathrm{~mL}$ de água destilada estéril. A solução de colagenase foi aplicada na região palmar do TFDS, no ponto médio localizado entre a borda distal do osso acessório do carpo e a proximal dos ossos sesamóides proximais, de forma a atingir o centro do tendão. O procedimento foi realizado com o auxilio de um transdutor linear de 7,5 MHz (Medison ${ }^{\circledR}$ ), sendo a indução considerada o início da fase experimental.

Para a obtenção do PRP foram realizadas modificações a partir do método descrito por Carmona (2006). Para isso, amostras de $81 \mathrm{~mL}$ do sangue de cada um dos animais foram colhidas por punção da veia jugular externa, em 18 tubos com capacidade para $4,5 \mathrm{~mL}$, contendo o anticoagulante citrato de sódio a $3,8 \%$. As amostras de sangue foram homogeneizadas e centrifugadas a $120 \mathrm{~g}$, durante cinco minutos. De cada tubo centrifugado foi descartado $1,5 \mathrm{~mL}$ do plasma presente na superfície, com o propósito de se usar um plasma mais concentrado em plaquetas na segunda centrifugação. Para isso, $20 \mathrm{~mL}$ do plasma obtido após a primeira centrifugação foram acondicionados em dois tubos sem anticoagulante, com $10 \mathrm{~mL}$ de capacidade, procedendo-se em seguida à centrifugação dos mesmos a $473 \mathrm{~g}$ por cinco minutos. Após a segunda centrifugação, o plasma foi dividido em duas frações: o sobrenadante (plasma pobre em plaquetas) e a fração remanescente denominada PRP. O plasma pobre foi descartado e o PRP, reservado. Deste, $2,5 \mathrm{~mL}$ foram acondicionados em um novo tubo a vácuo sem anticoagulante, para ativação. Para tal, foram adicionados $125 \mu \mathrm{L}$ de solução de cloreto de cálcio a $0,0125 \mathrm{~mol} . \mathrm{L}^{-1}$ (Wiener lab. ${ }^{\circledR}$ ). Posteriormente, o tubo com PRP foi incubado em estufa a uma temperatura de $20-22^{\circ} \mathrm{C}$, por duas horas, com a finalidade de estimular a degranulação plaquetária. Adicionalmente, procedeu-se nova centrifugação a $1.720 \mathrm{~g}$ por oito minutos, com a finalidade de se obter um PRP homogeneo após a ativação, ou seja, sem a presença de coágulos de fibrina que eventualmente pudessem vir a dificultar a aplicação intratendínea. Os tubos contendo o PRP ativado para aplicação intratendínea foram acondicionados em caixa de isopor com gelo identificada com o número do animal. A certificação da concentração de plaquetas no PRP foi realizada automaticamente, logo após a segunda centrifugação.

No $12^{\circ}$ dia após a indução da tendinite foi realizado o tratamento com o PRP. Na lesão efetuada no TFDS direito (grupo tratado, GT), foram administrados $2,5 \mathrm{~mL}$ do PRP ativado com cloreto de cálcio a $0,0125 \mathrm{~mol} . \mathrm{L}^{-1}$, contendo concentrações variando entre 320.000 e 500.000 plaquetas. $\mu \mathrm{L}^{-1}$. Já na tendinite do TFDS esquerdo (grupo controle, GC), foram injetados $2,5 \mathrm{~mL}$ de solução salina a $0,9 \%$ (Sanobiol ${ }^{\circledR}$ ). A administração intralesional em ambos os grupos foi realizada utilizando-se agulha de $21 \mathrm{G}$, monitorada por exame ultra-sonográfico.

Os animais foram submetidos à atividade física controlada e progressiva a partir do quinto dia de aplicação do PRP e da solução salina, tendo uma duração de 30 dias. O seguinte esquema foi utilizado: 5 minutos ao passo (10 dias); 10 minutos ao passo (10 dias) e, finalmente, 15 minutos ao passo durante 
outros 10 dias. Durante essa atividade, os animais foram puxados pelo cabresto.

O exame ultra-sonográfico foi realizado com equipamento portátil (Medison ${ }^{\circledR}$, modelo Sonovet 600 ) provido de transdutor linear de 7,5 MHz, acoplado a um standoff pad (distanciador) que proporcionaram o acompanhamento do TFDS antes da administração da colagenase, 48 horas após a indução da tendinite e no $7^{\circ}, 12^{\circ}, 14^{\circ}, 21^{\circ}, 28^{\circ}, 35^{\circ}$ e $42^{\circ}$ dias do experimento. As avaliações foram realizadas nos planos transversal e longitudinal, e as imagens obtidas foram registradas a partir de uma placa de captura de vídeo (Pixel View ${ }^{\circledR}$ ) instalada no computador, para posterior comparação entre os membros nos diferentes momentos avaliados. As variáveis ultra-sonográfica avaliadas foram:

a) Área transversal do tendão (ATT) e área transversal da lesão (ATL). A ATT e a ATL foram medidas $\left(\mathrm{cm}^{2}\right)$ a partir das imagens ultra-sonográficas obtidas no local de indução da tendinite, mediante a orientação de um ponto de sutura simples separado e marcação com o uso de uma caneta Texta fineline 700. As mensurações foram realizadas utilizando-se o software QUANT V1.0.0.28, desenvolvido pelo Departamento de Solos da Universidade Federal de Viçosa (MG), já padronizado para utilização no tendão de eqüinos por Aristizábal et al. (2005).

b) Percentual de área lesada no interior de cada tendão e intensidade da lesão. Para a determinação e avaliação dessas variáveis tomaram-se como base as informações descritas por Genovese \& Rantanen (1998). O percentual de área lesada foi obtido por meio da relação entre a área total da lesão e área transversal do tendão. A intensidade da lesão foi avaliada de acordo com o padrão de comprometimento descrito como: discreta: de $1-15 \%$ da ATT; moderada: de 16 a $25 \%$ da ATT e intensa: comprometimento acima de $25 \%$ da ATT.

c) Ecogenicidade da lesão. A ecogenicidade foi graduada de 0 a 4, segundo a classificação de Genovese et al. (1986): 0: padrão normal (isoecóico); (1) redução em 25\% (predominantemente isoecóico); (2) redução em 50\%; (3) redução em $75 \%$ (predominantemente anecóico); e (4) redução em 100\% do padrão isoecóico (totalmente anecóico).

d) Paralelismo das fibras colágenas. A determinação do paralelismo das fibras foi realizada nas imagens obtidas longitudinalmente e graduada em escala de 0 a 3, conforme descrito por Alves et al. (2001): 0 = ausência, 1 = discreto, 2 = parcial, 3 = paralelismo total.

Os dados referentes às variáveis ultra-sonográficas (área transversal do tendão e da lesão tendínea; ecogenicidade da lesão e paralelismo das fibras colágenas) foram avaliadas por meio de análises de regressões em função do tempo e do tratamento, estudado por uma variável dummy ( $\mathrm{GT}=1, \mathrm{GC}=0)$, cujos coeficientes foram testados pelo teste t a $5 \%$ de probabilidade. A análise foi realizada no programa estatístico Minitab ${ }^{\circledR}$ versão14, mediante o uso das médias das variáveis em estudo dos grupos experimentais GT e GC, nos diferentes tempos de avaliação após o tratamento.

Os procedimentos experimentais envolvendo animais foram submetidos à análise da Comissão de Ética do Departamento de Veterinária da Universidade Federal de Viçosa, e após aprovação receberam no de protocolo 73/2007.

\section{RESULTADOS}

O uso do distanciador proporcionou boa individualização do TFDS, particularmente nas imagens obtidas no plano transversal.
Nas avaliações realizadas previamente ao tratamento (dia zero, com 48 horas, assim como no $7^{\circ}$ e $12^{\circ}$ dia), os achados mais importantes nos tendões direito e esquerdo foram a presença de edema peritendíneo após 48 horas da indução da tendinite, a perda do paralelismo perfeito das fibras colágenas e a visualização inicial da lesão mediante a perda de ecogenicidade no $7^{\circ} \mathrm{dia}$, com meIhor delimitação no $12^{\circ}$ dia.

Após o tratamento (dias 14, 21, 28, 35 e 42), a única variável que diferiu $(P<0,05)$ entre o $\mathrm{GC}$ e o GT foi a área transversal da lesão (ATL), com menores valores médios no GT. Já a redução $(P<0,05)$ em função do tempo foi observada tanto para a ATL como para o grau de ecogenicidade da lesão em ambos os grupos (Fig.1 e 2). O mesmo comportamento não $(P>0,05)$ foi verificado nas demais variáveis ultra-sonográficas (ATT e paralelismo das fibras colágenas) em estudo.

A intensidade da lesão, baseada no percentual da ATL, foi classificada como discreta (1 a 15\% da ATT) em ambos os grupos até a última avaliação ultra-sonográfica (42ํㅜㅇ dia).

Em ambos os grupos a ecogenicidade da lesão apresentou-se hipoecóica, com perdas entre 25\% e 75\% (Grau 1 a 3) durante os diferentes momentos de avaliação pós-

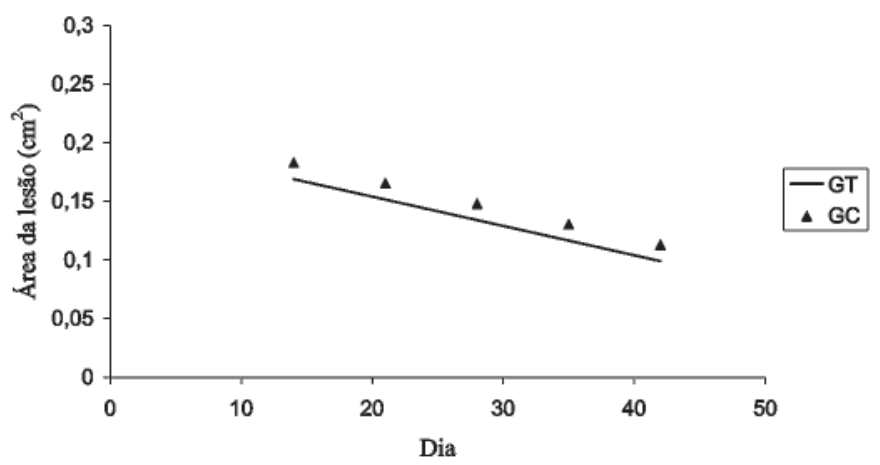

Fig.1. Estimativas da área da lesão nos grupos tratado (GT) e controle (GC) após o tratamento, em função do tempo de avaliação.

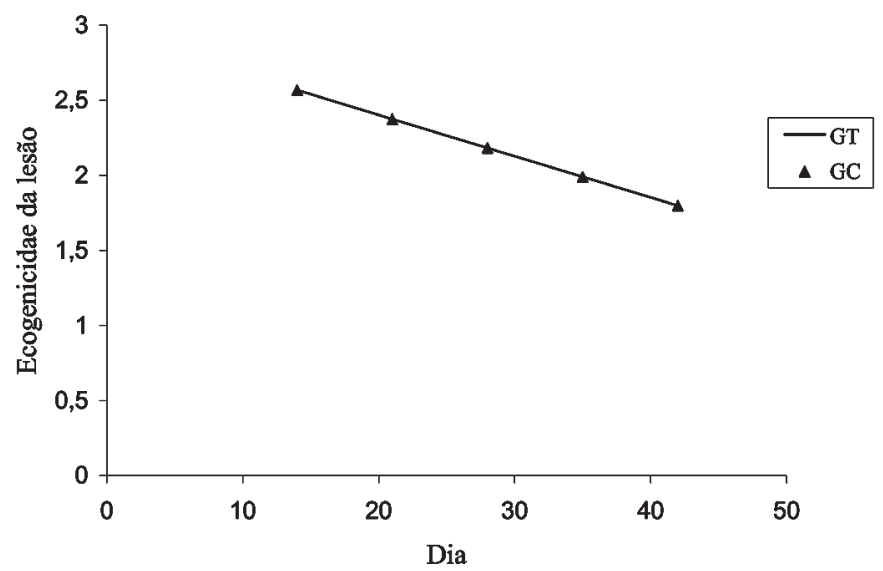

Fig.2. Estimativas do grau de ecogenicidade da lesão (0 a 4) nos grupos tratado (GT) e controle (GC) após o tratamento, em função do tempo de avaliação. 


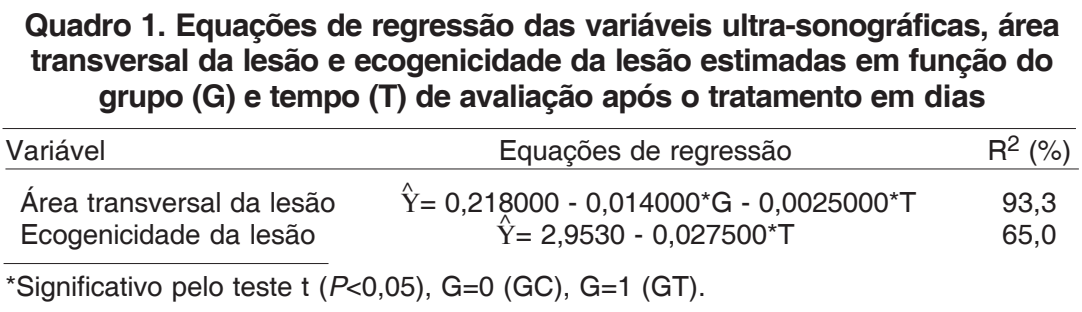

tratamento com PRP e administração de salina, mas sem diferenças $(P>0,05)$ entre os grupos. Durante esse mesmo período de avaliação ultra-sonográfica, o paralelismo das fibras colágenas manteve-se parcial (Grau 2) e diferenças $(P>0,05)$ entre grupos não foram observadas.

Os valores médios da área transversal do tendão variaram de $1,24 \pm 0,10$ a $1,53 \pm 0,15 \mathrm{~cm}^{2}$ no GT e de $1,34 \pm 0,18$ a $1,56 \pm 0,16 \mathrm{~cm}^{2}$ no $\mathrm{GC}$, sem que diferenças $(P>0,05)$ fossem observadas entre os grupos.

As equações de regressão utilizadas para a construção das Fig.1 e 2 estão apresentadas no Quadro 1. Notase a influência do tempo na redução das variáveis, assim como a diferença $(P<0,05)$, já mencionada anteriormente, com relação à área transversal da lesão, de acordo com o grupo.

\section{DISCUSSÃO}

A utilização do distanciador foi fundamental para a adequada delimitação e individualização do TFDS. Segundo Biller \& Myer (1988), este acessório é importante no estudo de estruturas superficiais, até mesmo quando se utilizam transdutores de alta freqüência, já que reduz ou impede a ocorrência de artefatos do tipo reverberação na imagem ultra-sonográfica.

As alterações ultra-sonográficas (edema peritendíneo e perda da ecogenicidade e do paralelismo linear das fibras colágenas) observadas até o $12^{\circ}$ dia de indução da tendinite, foram atribuídas à ação catabólica da colagenase sobre o tecido tendíneo. Esses achados corroboram com os de outros autores (Foland et al. 1992, Alves et al. 2001, 2002, Fernandes et al. 2003, Marxen et al. 2004), que também observaram modificações nos sonogramas do TFDS após administração da enzima.

Segundo Reef (1998), o edema peritendíneo pode desaparecer quando o processo inflamatório cessa, mas a evidência de tecido peritendíneo ecogênico é indicativo de inflamação persistente do tecido subcutâneo, com possibilidade de progressão para fibrose e desenvolvimento de aderências entre o tendão e as estruturas adjacentes.

A perda da ecogenicidade (padrão hipoecóico a anecóico) em lesões agudas do TFDS corresponde à presença de hemorragia, fibrinólise ou tecido de granulação inicial (Marr et al. 1993). Entretanto, a correlação de achados ultra-sonográficos associados a variação de tonalidade da cor cinza (ecogenicidade) com alterações histopatológicas foi questionada por Crass et al. (1992), que encontraram imagens ultra-sonográficas que permaneceram alteradas ainda que a histopatologia demonstrasse realinhamento fibrilar adequado e completa cicatrização da lesão. Este achado foi posteriormente confirmado por van Schie et al. (1998) ao realizarem estudo quantificando os efeitos de variáveis associadas ao aparelho ultra-sonográfico, como configuração do ganho, posição e deslocamento do transdutor. Essas informações revelam alguns dos possíveis equívocos que o exame ultra-sonográfico pode ocasionar.

A redução da ATL em membros tratados com PRP, conforme observado neste estudo entre o $14^{\circ}$ e o $42^{\circ}$ dias, também foi recentemente relatada por Argueles et al. (2008) em dois eqüinos com tendinite aguda do TFDS, submetidos a três tratamentos com concentrado de plaquetas a intervalos de duas semanas. Entretanto, o mesmo comportamento foi observado no GC do presente estudo, embora com maior $(P<0,05)$ área transversal da lesão em comparação com o GT.

A ocorrência de menor $(P<0,05)$ área da lesão no grupo tratado, conforme constatado no presente estudo, também foi observado por Redding et al. (1999), estudando oito eqüinos da raça Puro Sangue Inglês com tendinite, que foram tratados $(\mathrm{N}=4)$ com glicosaminoglicanos polissulfatados e avaliados durante oito semanas. A menor ATL observada no grupo tratado foi interpretada pelos autores como um efeito significativo do tratamento. Segundo Reef (1998), a diminuição dessa variável ultrasonográfica é indicativa de cicatrização e remodelação.

A não observação do paralelismo perfeito das fibras colágenas em ambos os grupos ao término do experimento foi atribuída ao período de avaliação ultra-sonográfica adotado no presente estudo para acompanhar a remodelação tendínea, que, segundo Dahlgren (2007) se inicia seis semanas após a lesão e estende-se por 6-12 meses ou mais, caracterizando-se pelo melhor alinhamento das fibras colágenas ao longo da linha de tensão e pela formação de ligações cruzadas entre as moléculas de colágeno, proporcionando importante resistência à tração. Nesse sentido, é possível que melhores resultados com relação ao paralelismo das fibras pudessem ser obtidos se os animais fossem avaliados por um período mais longo do que os 42 dias adotados neste estudo.

Reef et al. (1997), estudando 99 eqüinos com tendinite espontânea do TFDS com um a quatro meses de evolução, tratados com cinco aplicações de fumarato Baminopropionitrila (doses de 3, 5, 7 ou $8 \mathrm{mg}$ ) por via intralesional, constataram melhora $(P<0,05)$ no alinhamento das fibras colágenas após 16 semanas de efetuado o tratamento utilizando as maiores doses do fármaco. Esses resultados reafirmam a necessidade de maior período de avaliação para a obtenção de melhores informações ultra- 
sonográficas sobre o paralelismo das fibras. Entretanto, o período de estudo adotado no presente experimento foi semelhante ao utilizado por outros autores (Spurlock et al. 1989, Gaughan et al. 1995, Machado et al. 2000, Fernandes et al. 2003).

\section{CONCLUSÃO}

Os resultados obtidos no presente estudo permitem concluir que o PRP promove maior redução da área da lesão de tendinite induzida por colagenase, mensurada por ultrasonografia.

Agradecimentos.- Os autores agradecem à Coordenação de Aperfeiçoamento de Pessoal de Nível Superior (CAPES) pela concessão da bolsa de mestrado ao pesquisador Maia e à Fundação de Amparo à Pesquisa do Estado de Minas Gerais (FAPEMIG) pelo apoio financeiro. Adicionalmente, à empresa Nutricell por fornecer o distanciador.

\section{REFERÊNCIAS}

Alves A.L.G., Nicoletti J.L.M., Thomassian A., Hussni C.A. \& Watanabe M.J. 2002. Tratamento cirúrgico splitting nas tendinites agudas experimentais em eqüinos. Arch. Vet. Sci. 7(2):45-51.

Alves A.L.G., Rodrigues M.A.M., Borges A.S., Nicoletti J.L.M., Thomassian A. \& Hussni C.A. 2001. Influência do fumarato de betaaminoproprionitrila associada ao exercício na cicatrização tendínea eqüina. Avaliação clínica e ultra-sonográfica. Revta Educ. Contin. CRMV-SP 4(1):19-27.

Anitua E., Andia I., Ardanza B., Nurden P. \& Nurden A.T. 2004. Autologous platelet source of proteins for healing and tissue regeneration. Thromb. Haemost. 91(1):4-15.

Arguelles D., Carmona J.U., Climent F., Munõz E. \& Prades M. 2008. Autologous platelet concentrates as a treatment for musculoskeletal lesions in five horses. Vet. Rec. 162(7):208-211.

Aristizabal F.A.M., Souza M.V., Aranzales J.R.M. \& Ribeiro Junior J.I. 2005. Valores biométricos obtidos por ultra-sonografia dos tendões flexores e ligamentos acessório inferior e suspensório da região metacárpica palmar de cavalos Mangalarga Marchador. Arq. Bras. Med. Vet. Zootec. 57(2):156-162.

Barbosa A.L.T., Del Carlo R.J., Gomes H.C., Oliveira A.C., Monteiro B.Z. \& Del Carlo B.D. 2008. Plasma rico em plaquetas para a reparação de falhas ósseas em cães. Ciência Rural 38(5):1335-1340.

Biller D.S. \& Myer W. 1988. Ultrasound scanning of superficial structures using an ultrasound standoff pad. Vet. Radiol. Ultrasound 29(3):138142.

Camargo P.M., Lekovic V., Weinlaender M., Vasilic N., Madzarevic M. \& Kenney E.B. 2002. Platelet-rich plasma and bovine porous bone mineral combined with guided tissue regeneration in the treatment intrabony defects in humans. J. Periodontal Res. 37(4):300-306.

Carmona J.U. 2006. Use of autologous platelet concentrates for the treatment of muculoskeletal injuries in the horse. Thesis de Doctorado, Universitat Autonoma de Barcelona. UAB, Barcelona. 91p.

Crass J.R., Genovese R.L., Render J.A. \& Bellon E.M. 1992. Magnetic resonance, ultrasound and histopathologic correlation of acute and healing equine tendon injuries. Vet. Radiol. Ultrasound 33(4):206-216.

Dahlgren L.A. 2007. Pathobiology of tendon and ligament injuries. Clin. Tech. Equine Pract. 6:168-173.

Feldman B.F., Zinkl J.G. \& Jain N.C. 2000. Schalm's Veterinary Hematology. $5^{\text {th }}$ ed. Lippincott Williams and Wilkins, Philadelphia. 1344p.

Fernandes M.A.L., Alves G.E.S. \& Souza J.C.A. 2003. Efeito do ultrasom terapêutico em tendinite experimental de eqüinos: estudo clíni$\mathrm{co}$, ultra-sonográfico e histopatológico de dois protocolos. Arq. Bras. Med. Vet. Zootec. 55(1):1-11.
Foland J.W., Trotter G.W., Powers B.E., Wringley R.H. \& Smith F.W. 1992. Effect of sodium hyaluronate in collagenase-induced superficial digital flexor tendinitis in horses. Am. J. Vet. Res. 53(12):2371-2376.

Gaughan E.M., Gift L.J., De Bowes R.M., Basaraba R. \& Roush J. 1995. The influence of sequencial intratendinous sodium hyaluronate on tendon healing in horses. Vet. Comp. Orthop. Traumatol. 8:40-45.

Genovese R.L. \& Rantanen N.W. 1998 The superficial digital flexor tendon, p.289-398. In: Rantanen N.W. \& Mckinnon A.O. (Ed.), Equine Diagnostic Ultrasonography. Williams and Wilkins, Balti-more.

Genovese R.L., Rantanen N.W., Hauser M.L. \& Simpsom B.R. 1986. Diagnostic ultrasonography of equine limbs. Vet. Clin. North Am. Equine Pract. 2(1):145-226.

Gonshor A. 2002. Technique for producing platelet-rich plasma e platelet concentrate: Background and process. Int. J. Periodontics Restorative Dent. 22(6):547-557.

Kevy S.V. \& Jacobson M.S. 2004. Comparison of methods for point of care preparation of autologous platelet gel. J. Extra. Corpor.Technol. 36(1):28-35.

Machado M.V.M., Vulcano L.C., Hussni C.A. \& Alves A.L.G. 2000. Efeito da laserterapia em tendinite experimental no tendão flexor digital superficial em eqüinos: estudo histológico e ultra-sonográfico. Arch. Vet. Sci. 5:111-115.

Maia L. 2008. Plasma rico em plaquetas no tratamento de tendinite em eqüinos: avaliação clínica, ultra-sonográfica e histopatológica. Dissertação de Mestrado, Universidade Federal de Viçosa, Vicosa. 78p.

Marr C.M., McMillan I., Boyd J.S., Wright N.G. \& Murray M. 1993. Ultrasonographic and histopatological findings in equine superficial digital flexor tendon. Equine Vet. J. 25(1):23-29.

Marx R.E., Carlson E.R., Eischstaedt R.M., Schimmele S.R., Strauss J.E. \& Georgeff K.R. 1998. Platelet-rich plasma: Growth factor enhancement for bone grafts. Oral Surg. Oral Med. Oral. Pathol. Oral Radiol. Endod. 85(6):638-646.

Marxen S., Neto J.C.L., Canola J.C., Moraes J.R.E. \& Ribeiro G. 2004. Intralesional polysulphated glycosaminoglycan as treatment of equine collagenase induced tendinitis: Clinical, ultrasonographic and histopathologic evaluation. Arq. Bras. Med. Vet. Zootec. 56(6):701-708.

Minitab 14 Statistical Software 2004. Disponível em: <http:// www.minitab.com/products/minitab/14>. Acessado em Mar. 20, 2008.

Nunes Filho D.P., Luppino F., Yaedú R.Y.F. \& Carvalho P.S.P. 2007. Avaliação microscópica da ação do osso autógeno associado ou não ao PRP em cavidades ósseas de cães. Implant News 4(3):263-269.

Pagliosa G.M. \& Alves G.E.S. 2007. Considerações sobre a obtenção e o uso do plasma rico em plaquetas e das células mesenquimais indiferenciadas em enxertos ósseos. Ciência Rural 37(4):1202-1205.

Redding W.R., Booth L.C. \& Pool R.R. 1999. The effects of polysulphated glicosaminoglican o the healing of collagenase induced tendinitis. Vet. Comp. Orthop. Traumatol.12:48-55

Reef V.B. 1998. Equine diagnostic ultrasound. W.B. Saunders, Philadelphia. 560p.

Reef V.B., Genovese R.L. \& William M.D. 1997. Initial long-term results of horses with superficial digital flexor tendonitis treated with intralesional de B-aminopropionitrile Fumarate. Proc. 43를 Ann. Meet. Am. Assoc. Equine Pract., Arizona, p.301-305.

Spurlock G.H., Spurlock S.L. \& Parker G.A. 1989. Evaluation of hylartin $V$ therapy for induced tendinitis in the horse. J. Equine Vet. Sci. 9(5)242243.

van Schie J.T.M., Bakker E.M. \& van Weeren P.R. 1998. Ultrasonographic evaluation of equine tendons: A quantitative in vitro study of the effects of amplifier gain level, transducer-tilt and transducerdisplacement. Vet. Radiol. Ultrasound 39(5):151-160.

Wrigley R.H. 2006. Ultra-sonografia de tendões, ligamentos e articulações, p.417-601. In: Stashak T.S. (Ed.), Claudicação em eqüinos segundo Adams. 5a ed. Roca, São Paulo. 